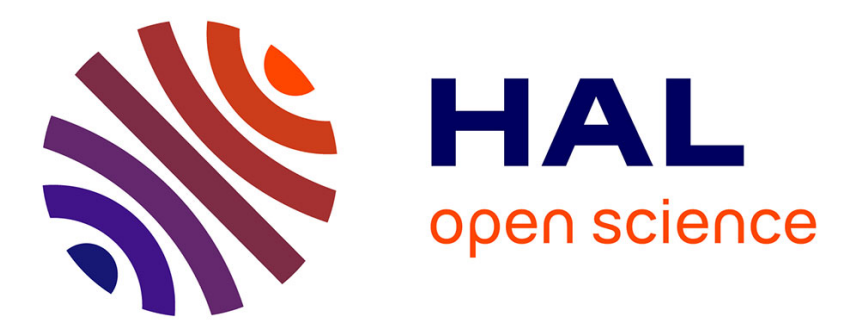

\title{
Benzoyl Shift: A New Approach to Reverse Regioselectivity in the Monoprotection of vic-Diols Aurélien de la Torre
}

Aurélien de La Torre, Camille Oger, Valérie Bultel-Poncé, Thierry Durand, Jean-Marie Galano

\section{To cite this version:}

Aurélien de La Torre, Camille Oger, Valérie Bultel-Poncé, Thierry Durand, Jean-Marie Galano. Benzoyl Shift: A New Approach to Reverse Regioselectivity in the Monoprotection of vic-Diols Aurélien de la Torre. SYNLETT, 2016, 10.1055/s-0035-1561496 . hal-02592806

\section{HAL Id: hal-02592806 https://hal.science/hal-02592806}

Submitted on 15 May 2020

HAL is a multi-disciplinary open access archive for the deposit and dissemination of scientific research documents, whether they are published or not. The documents may come from teaching and research institutions in France or abroad, or from public or private research centers.
L'archive ouverte pluridisciplinaire HAL, est destinée au dépôt et à la diffusion de documents scientifiques de niveau recherche, publiés ou non, émanant des établissements d'enseignement et de recherche français ou étrangers, des laboratoires publics ou privés. 


\section{Benzoyl Shift: A New Approach to Reverse Regioselectivity in the Monoprotection of vic-Diols}

\author{
Aurélien de la Torre \\ Camille Oger* \\ Valérie Bultel-Poncé \\ Thierry Durand \\ Jean-Marie Galano*
}

Institut des Biomolécules Max Mousseron (IBMM) UMR CNRS 5247-University of Montpellier, ENSCM, Faculté de Pharmacie, 15 Av. Charles Flahault, 34093 Montpellier cedex 05, France jean-marie.galano@univ-montp1.fr

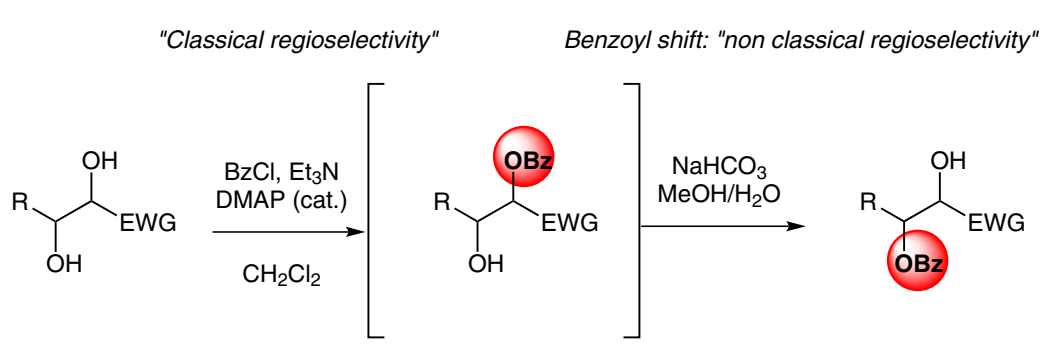

al. ${ }^{5}$ generating $\beta$-protected ester $\mathbf{2}$ and $\alpha$-protected ester $\mathbf{3}$ in a $4: 1$ mixture of regioisomers. However, we observed that following the next step, namely an acidic cleavage of the acetonide, only the $\beta$ regioisomer was recovered in

(a)

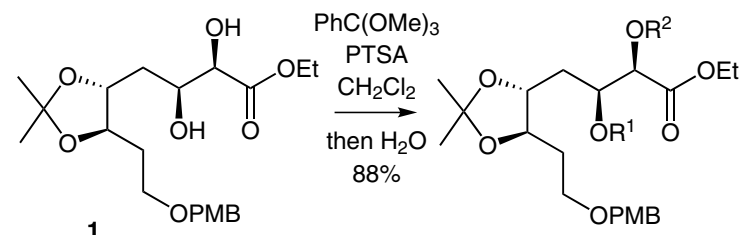

Regioselective transformations of diols are ubiquitous in organic synthesis. ${ }^{1}$ For this purpose, it is often necessary to use selective protecting technologies to block the reactivity of one hydroxyl group. ${ }^{2}$ For example, acetyl and benzoyl protecting groups can be used to protect selectively one hydroxyl group in 1,2- or 1,3-diol systems. ${ }^{3}$ In the case of $\alpha, \beta-$ dihydroxyesters, the $\alpha$-alcohol can be regioselectively protected by an acetyl or benzoyl moiety using the corresponding acyl chloride and an amine base at low temperature. ${ }^{4}$ Nevertheless, to the best of our knowledge, only three methods allow regioselective protection of the $\beta$-alcohol with an acetyl or benzoyl moiety, ${ }^{5-7}$ one of them being an enzymatic method, ${ }^{6}$ the scope of which is limited to one substrate. Among the two others, one requires the use of trimethyl orthobenzoate under acidic conditions induced by PTSA, ${ }^{5}$ while the other one relies on the use of dibutyltin oxide and an acyl chloride. ${ }^{6}$ An alternative approach would be to protect both hydroxyl functions and then regioselectively deprotect the $\alpha$-alcohol; although this last strategy would be clumsy and not atom-economic. Herein, we describe a new mild method for the regioselective protection of vic-diols.

In the course of our recent total synthesis of dihomoisofuran, we chose to protect $\alpha, \beta$-dihydroxyester 1 regioselectively at the $\beta$ position, ${ }^{8}$ using the method of Oikawa et 
good yield (Scheme 1, a). NMR monitoring of the acidic deprotection of pure $\alpha$-protected ester 3 was performed in deuterated methanol and water, which only revealed the deprotection of the acetonide leading to compound $\mathbf{5}$. Therefore, we realized that basic workup of the reaction (10 equiv solid $\mathrm{NaHCO}_{3}$ ) initiated the migration of the benzoyl moiety from the $\alpha$ to the $\beta$ position (Scheme 1, b). This phenomenon can be explained by the relative acidity of the $\alpha$ alcohol, which makes it a good leaving group during the migration process. Thus, we originally envisaged a one-flask protocol to protect the least acidic alcohol regioselectively in a vic-diol (Scheme 2 ).

Table 1 Scope of the Regioselective Benzoylation

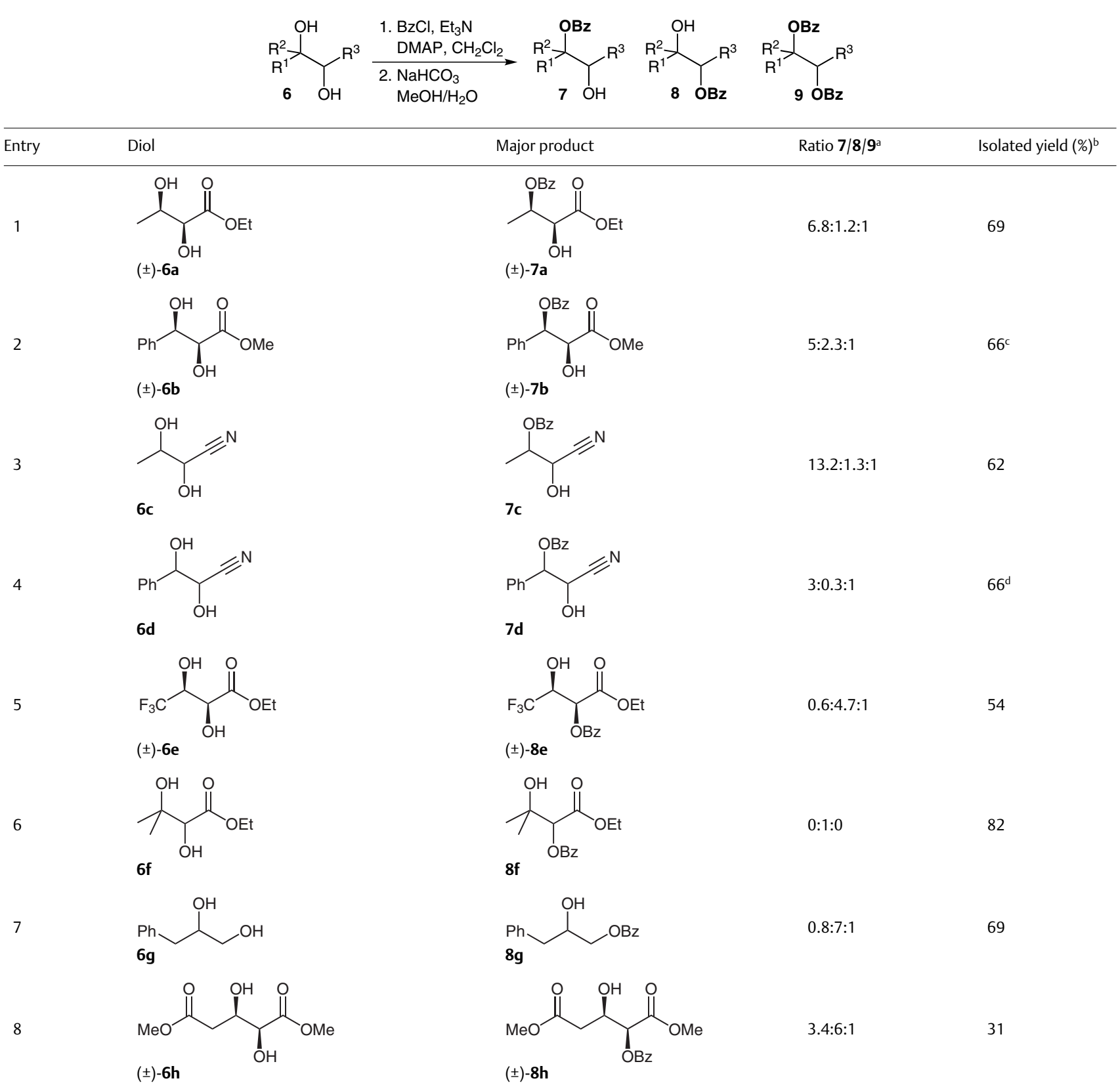

${ }^{d}$ Isolated as a 13:1 mixture of 7d and $\mathbf{8 d}$. 


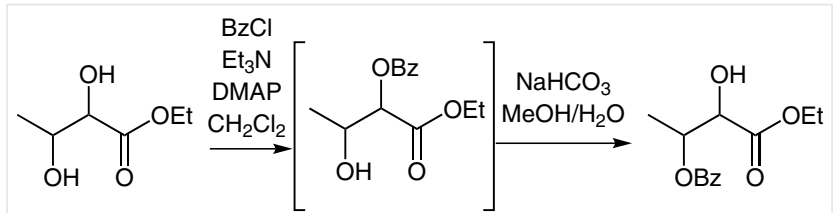

Scheme 2 Proposed strategy for the $\beta$-protection of $\alpha, \beta$-dihydroxy esters

The plan was to perform a monoacylation of vic-diols using a cheap and straightforward procedure without concern for the selectivity of the protection followed by basic workup to initiate the benzoyl shift. The initial protection was achieved using a standard procedure; that is, benzoyl chloride and triethylamine in dichloromethane, catalyzed by DMAP at $0{ }^{\circ} \mathrm{C}$ to room temperature over three hours. ${ }^{4}$ However, under these conditions, the subsequent one-flask basic workup ( 10 equiv solid $\mathrm{NaHCO}_{3}$ ) needed to perform the benzoyl shift led to unreproducible results in the migration. After experimentation, it was found that an acidic workup was necessary to avoid reproducibility issues, eliminating the possibility to perform a one-flask transformation. Therefore the second step for that latter stage was performed with solid $\mathrm{NaHCO}_{3}$ (5 equiv) in $\mathrm{MeOH}-\mathrm{H}_{2} \mathrm{O}$ (9:1, $\mathrm{v} / \mathrm{v}) .{ }^{9}$ The use of different bases $\left(\mathrm{KHCO}_{3}, \mathrm{Na}_{2} \mathrm{CO}_{3}\right)$ did not improve the migration. Thanks to this procedure, syn-ethyl2,3-dihydroxybutanoate was regioselectively monoprotected on the $\beta$-position with a $6.8: 1.2$ ratio and $69 \%$ yield of the desired isomer (Table 1 , entry 1 ),$^{10}$ while the initial benzoylation gave a 1.8:10.2 ratio in favour of the $\alpha$ position. Interestingly, the procedure by Oikawa et al. gave a similar yield and ratio, even if in our case we also observed bisprotection inherent in our straightforward initial protection conditions. However, benzoylation at lower temperature $\left(-78{ }^{\circ} \mathrm{C}\right)$ can minimize the bisprotection ratio if the diol substrate is valuable. No epimerization was observed during the reaction.

A number of other vic-diols was tested under these conditions. Ethyl syn-2,3-dihydroxy-3-phenylpropanoate could also be protected on the $\beta$-position, although with lower regioselectivity (Table 1 , entry 2 ). It appears that $\alpha, \beta$-dihydroxy nitriles can also be regioselectively protected on the $\beta$ position (Table 1, entries 3 and 4 ). ${ }^{11}$ The presence of a nitrile function instead of the ester improves the regioselectivity of the reaction. Again, substantially better regioselectivity was observed with a methyl rather than a phenyl substituent in the $\beta$-position. Interestingly, when a highly electron-withdrawing group was present in the $\beta$-position, no migration was observed. Thus, in the case of ethyl 4,4,4trifluoro-2,3-dihydroxybutanoate, the major product has the benzoyl moiety on the $\alpha$ position (Table 1 , entry 5 ). Comparative NMR analysis before and after the basic workup showed the same ratio, meaning that the first step is regioselective for the $\alpha$-position and that no benzoyl shift occurs in this specific case. Moreover, with this substantially more electrophilic substrate, we also observed traces of transesterification of the ethyl ester by methanol as a byproduct. When one hydroxyl function is more sterically hindered than the other, such as in the case of a tertiary alcohol vs. a secondary one (Table 1 , entry 6 ) or in the case of a secondary alcohol vs. a primary one (Table 1 , entry 7 ), the benzoyl shift does not take place and the protecting group stays on the less substituted alcohol. Finally, in the case of a substrate containing two ester moieties, low yields are obtained, probably due to undesired side reactions such as lactonization (Table 1 , entry 8 ).

The regioselectivity of the benzoyl shift can be explained by the superior leaving-group ability of the $\alpha$-hydoxyl group in comparison to the $\beta$-hydroxyl. To assess this hypothesis, $\mathrm{p} K_{\mathrm{a}}$ calculations were made on the various substrates studied in the scope of the reaction (Table 2). ${ }^{12}$ Indeed, the results show a high correlation between the relative $\mathrm{p} K_{\mathrm{a}}$ of the two hydroxyl functions and the regioisomeric ratio of the benzoyl-substituted compounds. Remarkably, the reverse regioselectivity in the case of an ester with a $\mathrm{CF}_{3}$ substituent in the $\beta$-position matches with the $\mathrm{p} K_{\mathrm{a}}$ calculation that shows the $\beta$-hydroxyl group is more acidic (Table 2 , entry 5 ). This acidity-controlled shift is limited by steric hindrance (Table 2, entries 6 and 7), or when side reactions can occur (Table 2, entry 8).

Table 2 Relative $\mathrm{p} K_{\mathrm{a}}$ of the Hydroxyl Functions<smiles>[R]C([B])C([R])([R])O</smiles>

\begin{tabular}{llcc}
\hline Entry & Ratio 7/8/9 & $\mathrm{p} K_{\mathrm{a}}(\mathbf{A})^{\mathrm{a}}$ & $\mathrm{p} K_{\mathrm{a}}(\mathbf{B})^{\mathrm{a}}$ \\
\hline 1 & $6.8: 1.2: 1$ & $14.75^{\mathrm{b}}$ & $12.87^{\mathrm{b}}$ \\
2 & $5: 2.3: 1$ & $13.83^{\mathrm{b}}$ & $12.33^{\mathrm{b}}$ \\
3 & $13.2: 1.3: 1$ & $14.22^{\mathrm{b}}$ & $11.04^{\mathrm{b}}$ \\
4 & $3: 0.3: 1$ & $13.34^{\mathrm{b}}$ & $10.63^{\mathrm{b}}$ \\
5 & $0.6: 4.7: 1$ & $11.24^{\mathrm{b}}$ & $12.46^{\mathrm{b}}$ \\
6 & $0: 1: 0$ & $14.82^{\mathrm{c}}$ & $12.94^{\mathrm{b}}$ \\
7 & $0.8: 7: 1$ & $15.55^{\mathrm{b}}$ & $14.43^{\mathrm{b}}$ \\
8 & $3.4: 6: 1$ & $13.36^{\mathrm{b}}$ & $12^{\mathrm{b}}$ \\
\hline $\mathrm{a} \mathrm{p} K_{\mathrm{a}}$ calculated using ACDLabs 12.0. & & \\
$\mathrm{b} \pm 0.20$. & & & \\
${ }^{\mathrm{c}} \pm 0.29$. & & & \\
\end{tabular}

In conclusion, we have described a simple and convenient method for the regioselective monoprotection of activated vic-diols, using only inexpensive and readily available reagents. This method is a complementary approach to the one described by Oikawa et al. because it gives similar ratios but can be performed faster and cheaper. The regioselectivity of the reaction is guided by the relative acidity of the hydroxyl functions, when both are equally hindered. 


\section{Acknowledgment}

We gratefully acknowledge the University of Montpellier (Grants BQR 2011 and doctoral fellow of A.D.T.).

\section{Supporting Information}

Supporting information for this article is available online at http://dx.doi.org/10.1055/s-0035-1561496.

\section{References and Notes}

(1) For selected examples, see: (a) Friesen, R. W.; Vanderwal, C. J. Org. Chem. 1996, 30, 9103. (b) Barton, D. H. R.; Zhu, J. Tetrahedron 1992, 48, 8337. (c) Takasu, M.; Naruse, Y.; Yamamoto, H. Tetrahedron Lett. 1988, 29, 1947. (d) Ren, B.; Rahm, M.; Zhang, X.; Zhou, Y.; Dong, H. J. Org. Chem. 2014, 79, 8134. (e) Lee, D.; Williamson, C. L.; Chan, L.; Taylor, M. S. J. Am. Chem. Soc. 2012, 134, 8260. (f) Oger, C.; Marton, Z.; Brinkmann, Y.; Bultel-Poncé, V.; Durand, T.; Graber, M.; Galano, J.-M. J. Org. Chem. 2010, 75, 1892. (g) Cruz Silva, M. M.; Riva, S.; Sá e Melo, M. L. Tetrahedron 2005, 61, 3065. (h) Sureshan, K. M.; Shashidhar, M. S.; Praveen, T.; Das, T. Chem. Rev. 2003, 103, 4477. (i) Wang, G.; Ella-Menye, J.-R.; St. Martin, M.; Yang, H.; Williams, K. Org. Lett. 2008, 10, 4203.

(2) Wuts, P. G. M.; Greene, T. W. Greene's Protective Groups in Organic Synthesis; John Wiley and Sons: New York, 2007, 4th ed..

(3) For selected examples, see: (a) Bianco, A.; Brufani, M.; Melchioni, C.; Romagnoli, P. Tetrahedron Lett. 1997, 38, 651. (b) Ikejiri, M.; Miyashita, K.; Tsunemi, T.; Imanishi, T. Tetrahedron Lett. 2004, 45, 1243. (c) Mycock, D. K.; Sherlock, A. E.; Glossop, P. A.; Hayes, C. J. Tetrahedron Lett. 2008, 49, 6390.
(4) (a) Trost, B. M.; Yang, H.; Probst, G. D. J. Am. Chem. Soc. 2004, 126, 48. (b) Fleming, P. R.; Sharpless, K. B. J. Org. Chem. 1991, 56, 2869. (c) de la Torre, A.; Lee, Y. Y.; Massoni, A.; Guy, A.; BultelPoncé, V.; Durand, T.; Oger, C.; Lee, J. C.-Y.; Galano, J.-M. Chem. Eur. J. 2015, 21, 2442.

(5) Oikawa, M.; Wada, A.; Okazaki, F.; Kusumoto, S. J. Org. Chem. 1996, 61, 4469.

(6) Park, J. N.; Ko, S. Y. Bull. Korean Chem. Soc. 2002, 23, 507.

(7) Kirschning, A.; Kreimeyer, M.; Blanke, H.-P. Tetrahedron: Asymmetry 1993, 4, 2347.

(8) de la Torre, A.; Lee, Y. Y.; Oger, C.; Sangild, P. T.; Durand, T.; Lee, J. C.-Y.; Galano, J.-M. Angew. Chem. Int. Ed. 2014, 53, 6249.

(9) See the Supporting Information for a NMR monitoring of the basic workup that evidences the benzoyl shift.

(10) General Procedure for Monoprotection

To a solution of diol $(1 \mathrm{mmol})$ in $\mathrm{CH}_{2} \mathrm{Cl}_{2}(4 \mathrm{~mL})$ at $0{ }^{\circ} \mathrm{C}$ were added $\mathrm{Et}_{3} \mathrm{~N}$ (2.2 mmol), DMAP $(0.05 \mathrm{mmol})$, then slowly $\mathrm{BzCl}$ $(1.1 \mathrm{mmol})$, and the reaction was allowed to warm to r.t. over 3 $\mathrm{h}$. The reaction was quenched by addition of aq $\mathrm{HCl}(0.1 \mathrm{M}, \mathrm{ca} .3$ $\mathrm{mL}$ ), EtOAc was added (ca. $2 \mathrm{~mL}$ ), the organic phases separated and the aqueous phases extracted with EtOAc $(3 \times 2 \mathrm{~mL})$. The combined organic phases were dried over $\mathrm{MgSO}_{4}$, filtered, and concentrated under vacuum. The crude product was dissolved in $\mathrm{MeOH}-\mathrm{H}_{2} \mathrm{O}(4 \mathrm{~mL}, 9: 1 \mathrm{v} / \mathrm{v})$, solid $\mathrm{NaHCO}_{3}(5 \mathrm{mmol})$ was added to the solution, and the reaction was stirred for $90 \mathrm{~min}$ at r.t. Water was added (ca. $4 \mathrm{~mL}$ ), then EtOAc followed by extraction of the aqueous phase (3 times total). The combined organic phases were dried over $\mathrm{MgSO}_{4}$, filtered, and concentrated under vacuum. The crude product was purified by column chromatography.

(11) Compounds $\mathbf{6 c}$ and $\mathbf{6 d}$ were used as a mixture of syn- and antidiols.

(12) $\mathrm{p} K_{\mathrm{a}}$ calculations were performed using ACDLabs. 